\title{
Introducción al viaducto sobre el río Almonte en la línea de alta velocidad ferroviaria Madrid-Extremadura
}

\author{
Pablo Jiménez Guijarro \\ Ingeniero de Caminos, Canales y Puertos. Director de las obras. Subdirector de Construcción III
}

En la vida vos podés hacer dos cosas contrarias: o tender puentes o levantar muros. Los muros separan, dividen. Los puentes acercan.

En el año 2017, se cumplieron los 25 años desde que en abril de 1992 se inauguró la primera línea de alta velocidad en España. Durante estos veinticinco años, hemos sido capaces de desarrollar uno de los ferrocarriles más modernos y avanzados del mundo.

Dentro de este gran despliegue de infraestructuras que suponen las distintas líneas de alta velocidad construidas y en construcción, se han ejecutado cientos de estructuras, muchas de ellas espectaculares y siempre dando un paso más allá, como en el caso del viaducto del Almonte.

Cuando uno afronta un reto de la magnitud del viaducto del Almonte, en su interior siente un cúmulo de sensaciones.

Por un lado orgullo. Para cualquier profesional de nuestro sector participar en un proyecto de esta envergadura es un orgullo. Estamos hablando de superar retos que hasta ahora nadie ha superado y llegar a donde nadie ha llegado dentro del mundo de la ingeniería de puentes de alta velocidad.

Es este llegar a donde nadie ha llegado lo que hace que este orgullo se mezcle con el miedo. Miedo a lo desconocido y a todos los problemas que de momento desconoces pero que intuyes que vas a tener.

Si bien este miedo lo afrontas con ilusión. Ilusión que crece día a día cuando vas viendo que los arduos esfuerzos se van plasmando en el avance de la obra. Una obra que es un ente vivo, con sus ritmos propios, sus peculiaridades y sus manías. Ninguna obra es igual a otra y en nuestro caso con más motivo, puesto que el reto de hacer un puente de estas características no había sido abordado por nadie hasta ahora.

Extremadura es tierra de puentes. Y dentro de los puentes, sin desmerecer otras tipologías, es tierra de puentes arco, desde tiempos de los romanos hasta la actualidad. En las proximidades de donde se ha ejecutado el viaducto, existe todo un catálogo de puentes, ninguno de los cuales desmerece al anterior.

En la proximidad del viaducto de alta velocidad estaba en época romana el puente de Alconétar, cuyos restos podemos contemplar en la cola del embalse de Alcántara después de su traslado, para evitar que quedase inundado. En ellos se pueden observar arcos rebajados, conservándose dos arcos primitivos de 6.70 y 7.10 metros de luz.

En el mismo entorno, la autovía A-66 nos deleita con dos grandes puentes arco, uno de hormigón armado en el mismo río Almonte de 184 metros de luz y otro en el río Tajo, cuyo arco metálico tienen una luz de 234 metros.

El propio ADIF AV construye un puente arco de hormigón de 324 metros de luz entre apoyos en el río Tajo, y aguas abajo de los viaductos de $\mathrm{ADIF} A \mathrm{~A}$, nos encontramos con dos grandes viaductos para uso mixto de carretera y ferrocarril, que si bien no son arcos, fueron un referente en su momento por su ejecución por voladizos sucesivos.

Así, sin olvidar otros grandes puentes que existen en Extremadura, como el romano de Mérida, el puente Lusitania (arco superior de 180 metros de luz) también en Mérida, el puente de Medellín o los puentes de Badajoz (puente de Palmas, puente Real...), ya más alejados de la zona, siguiendo aguas abajo el río Tajo, nos encontramos con una de las grandes maravillas de la ingeniería romana, el puente de Alcántara, obra maestra de Cayo Lacer, que desde el año 104 D.C ve pasar al rio Tajo por sus arcos de 28.80 metros de luz máxima, y que 1914 años después, tal como aseveró el insigne Carlos Fernando Casado, sigue acreditando poseer las tres cualidades que Vitruvio exigía a toda edificación: firmitas, utilitas y venustas.

Es en este entorno, por donde transcurre la línea de alta velocidad Madrid-Extremadura-Frontera Portuguesa, comúnmente llamada línea de alta velocidad Madrid - Extremadura, línea de alta velocidad de tráfico mixto, cuyo objetivo último es conectar las capitales de España y Portugal.

La línea originariamente está concebida con vía doble electrificada, con ancho internacional (1435 mm) y con una velocidad de diseño de $350 \mathrm{~km} / \mathrm{h}$. En la configuración de la línea con conexión a la LAV Madrid - Sevilla en Pantoja, tiene una longitud de 437 km, si bien esta longitud está pendiente del nuevo estudio informativo de la LAV en Castilla La Mancha, que puede contemplar que la línea se conecte en Toledo y no en Pantoja. 
En 2008 el Gobierno de Portugal se desvinculó temporalmente del proyecto debido a la crisis económica que especialmente atravesaba Portugal suspendiendo las obras en su territorio, si bien en 2018 ha dado un nuevo impulso a la línea, aunque con variaciones frente al proyecto original.

Es en este contexto de crisis cuando se decide que entre Plasencia y Badajoz se monte en una primera instancia una vía única de ancho ibérico con traviesa polivalente, de manera que en el futuro el paso a ancho internacional sea rápido, sencillo y con un bajo coste. Para acceder a las estaciones, se plantean conexiones entre la LAV y la linea existente.

Posteriormente se decide que se montará vía doble entre Plasencia y Cáceres y entre Cáceres y Mérida y que se electrificará la línea desde Plasencia hasta Badajoz, puesto que es en este tramo donde las obras están más adelantadas, dejando el resto de la línea para una segunda fase.

Las instalaciones de seguridad contarán con GSMR y ERTMS nivel 2, usando ASFA como respaldo.

Dentro de la provincia de Cáceres, el tramo cruza el río Almonte en una zona donde se presenta un ensanchamiento del mismo al estar ya dentro del embalse de Alcántara, mediante un gran puente arco.

Se trata de un gran arco de hormigón de 384 m de luz entre los apoyos, situados fuera del embalse.

El viaducto tiene una longitud de 996 m y el elemento más emblemático de este viaducto es el arco de $384 \mathrm{~m}$ de luz entre apoyos, elevándose sobre sus cimentaciones a una altura superior a $65 \mathrm{~m}$ y sobre el nivel medio del embalse más de $80 \mathrm{~m}$.

El arco está formado por una sección octogonal hueca, tipo cajón de canto variable, en sus 210 m centrales, bifurcándose a continuación en dos pies por cada orilla, hasta plantar la estructura sobre sus arranques separados $19 \mathrm{~m}$ para dotarlo de la estabilidad necesaria. Es decir, el gran arco no es un una estructura clásica de configuración plana, sino un arco apoyado sobre cuatro verdaderas patas, en cuatro puntos convenientemente separados entre sí. Con esta configuración se consigue una estructura estable frente al empuje del viento y frente a los fenómenos dinámicos originados por el paso de los trenes a gran velocidad.

En el arranque de cada uno de los cuatro pies del arco el canto es de $6,9 \mathrm{~m}$ y la anchura de $3,7 \mathrm{~m}$. En la clave, punto más alto del arco, la sección se reduce hasta un canto de $4,8 \mathrm{~m}$ y $6 \mathrm{~m}$ de ancho, favoreciendo el conjunto del diseño la estabilidad global de la estructura, cuyo comportamiento aerodinámico ha sido verificado en el túnel de viento de la Universidad de Western Ontario.

El tablero permite alojar la plataforma de la doble vía de alta velocidad, así como otros elementos necesarios para el funcionamiento de la línea de ferrocarril. El ancho inferior del cajón coincide precisamente con el tamaño del arco en su clave a fin de unirse de forma limpia. Además, el tablero se dota de voladizos laterales que completan la anchura total de la sección hasta los $14 \mathrm{~m}$.

Las pilas tienen sección octogonal y una altura variable para adaptarse al perfil del trazado, alcanzándose alturas superiores a los $60 \mathrm{~m}$ en la zona más cercana al cruce del río.

Un aspecto a destacar del viaducto es el recurso a hormigones de alta resistencia. Así, para la ejecución del arco se ha usado un hormigón de $800 \mathrm{~kg} / \mathrm{cm}^{2}$ de resistencia a compresión, que además tiene la cualidad de ser autocompactante.

En cuanto a las cimentaciones del arco, pilas de vanos de acceso y estribos, se resuelven mediante grandes zapatas que buscan un sustrato rocoso de suficiente resistencia para repartir las cargas que reciben.

La construcción del arco se realiza por voladizos sucesivos. Es- tos voladizos se atirantan inicialmente desde las pilas de hormigón ubicadas en los arranques del arco y, después, desde dos torres de atirantamiento provisional de acero, de aproximadamente 50 metros de altura, situadas sobre dichas pilas. Cada pila y cada torre se retienen desde las cimentaciones de las pilas próximas, que precisan de anclaje al terreno.

La construcción del tablero se realiza por medio de sendas cimbras autoportantes superiores que se desplazan desde ambos estribos. Estas autocimbras son encofrados apoyados sobre las pilas construidas previamente, y sostienen vanos completos de hasta $45 \mathrm{~m}$ de longitud.

Los medios auxiliares necesarios para la construcción del arco son dos torres metálicas de más de $50 \mathrm{~m}$ de altura colocadas sobre las pilas extremas del arco; un carro de hormigonado para cada semiarco; un sistema de tirantes de acero que soporta el semiarco construido anclándose en la parte superior de la pila y en la torre; otro sistema de tirantes que soporta la pila y la torre anclándose en las cimentaciones de las pilas adyacentes, $y$, finalmente, un sistema de anclajes provisionales al terreno para sujetar las zapatas de las pilas adyacentes.

El importe total aproximado de esta gran obra de ingeniería es de aproximadamente 63 Millones de Euros (Base Imponible).

Un proyecto de la magnitud y de la complejidad técnica como es el viaducto del Almonte es el resultado del trabajo de un gran equipo de personas que han tomado parte en las distintas fases del proyecto, desde su concepción y diseño, hasta la ejecución de la obra.

El proyecto fue redactado por la UTE IDOM - Arenas, comandado por D. Juan José Arenas de Pablo, siendo la dirección del proyecto por parte del equipo de proyectos de ADIF de D. Ignacio Meana.

La obra ha sido ejecutada por la UTE formada por FCC Construcción y Conduril, estando al frente de un potente equipo multidisciplinar D. Pedro Cavero de Pablo, destacando D. David Carnero Pérez, D. Jose Luis del Valle Sánchez-Prieto y D. Agustín Alonso Velasco.

El proyecto de diseño y la adaptación a los medios constructivos fue realizado por los Servicios Técnicos de FCC, comandados por D. David Arribas Mazarracín.

La asistencia técnica a la obra fue realizada por la UTE formada por Idom y Arenas y Asociados, comandados por D. José Antonio Carrascosa Mata. El equipo de estructuras, que en todo momento asesoró y aconsejo a la dirección de obra, fue comandado por D. Guillermo Capellán Miguel, con la colaboración de D. Emilio Merino Rasillo y D. Javier Martínez Aparicio.

Por parte de construcción de ADIF AV son muchas las personas que han aportado su granito de arena al proyecto, habiendo destacado la ayuda inestimable que siempre me han prestado Dña. Eva María Sánchez-Montero Velasco y en una fase posterior la de D. Juan Miguel Figueroa Yáñez.

Asimismo, otras muchas personas han aportado su ayuda y conocimiento a este gran proyecto. A todos los que de una forma $\mathrm{u}$ otra habéis participado, quiero daros las gracias por vuestro esfuerzo y dedicación Han sido muchos días y muchas horas de intenso trabajo, momentos de dudas, momentos de incertidumbres, momentos duros y otros alegres, que al final son con los que nos quedamos más gratamente en el recuerdo. Entre todos hemos llevado la obra a su culminación. Y he de decir que para mí ha sido un orgullo dirigir esta obra con este gran grupo de profesionales involucrados.

Pablo Jiménez Guijarro

Ingeniero de Caminos, Canales y Puertos.

Director de las obras. Subdirector de Construcción III 